Check for updates

Cite this: RSC Adv., 2019, 9, 29424

Received 22nd August 2019

Accepted 10th September 2019

DOI: 10.1039/c9ra07216k

rsc.li/rsc-advances

\section{Efficient synthesis of spirooxindolyl oxazol-2(5H)- ones via palladium(II)-catalyzed addition of arylboronic acids to nitriles $\uparrow$}

\author{
Hao Song, ${ }^{a} \mathrm{Na}$ Cheng, ${ }^{a}$ Li-Qin She, ${ }^{a}$ Yi Wu*b and Wei-Wei Liao (D) *a
}

A versatile synthesis of spirooxindolyl oxazol-2(5H)-ones via palladium(॥)-catalyzed addition of arylboronic acids to nitriles is described. A wide range of spirooxindolyl oxazol-2(5H)-ones and other spirocyclic frameworks incorporating the oxazol-2(5H)-one unit can be readily prepared in good to high yields under the optimal conditions.
Rapid and efficient construction of pharmaceutical and biologically relevant compounds plays a very important role in modern organic synthesis, and constitutes the original impetus for the development of various novel synthetic approaches. The efficient construction of spirocyclic frameworks has been a topic of great relevance in organic synthesis due to their inherent three-dimensional architectures and the pronounced biological activities. ${ }^{1}$ In particular, the spirocyclic oxindoles have emerged as attractive synthetic targets because of their prevalence in numerous natural and unnatural products. ${ }^{2}$ Notably, the enhanced biological activities have been observed by the incorporation of a spiro five-membered azaheterocyclic ring at the $\mathrm{C} 3$ position of the oxindole core (Fig. 1). ${ }^{3}$ Thereby, a variety of synthetic methods have been developed to access analogous compounds possessing such privileged structure moieties. $^{4}$

As one of the important $\mathrm{N}-\mathrm{O}$ heterocyclic compounds, oxazolidinones and their derivatives have been widely used not only as synthetic building blocks, ${ }^{5}$ but also as pharmaceuticals ${ }^{6}$ and agrochemicals, ${ }^{7}$ owing to a diverse range of biological activities. ${ }^{8}$ Although great contributions have been made to access these valuable scaffolds, ${ }^{9}$ the construction of structurally diverse spirooxindolyl oxazol-2(5H)-ones, characterized by a spiro ring fusion at the $\mathrm{C} 3$ position of the oxindole core with oxazol-2 $(5 H)$-one motif, has received less attention from synthetic community, ${ }^{10}$ despite the fact that these spirocyclic heterocycles could be promising candidates possessing biological responses. In 2017, He and co-workers reported a formal $[3+2]$ cycloaddition reaction of in situ generated azaoxyallyl

${ }^{a}$ Department of Organic Chemistry, College of Chemistry, Jilin University, Changchun 130012, P. R. China. E-mail: wliao@jlu.edu.cn

${ }^{b}$ School of Pharmaceutical Science, Jilin University, Changchun 130012, P. R. China. E-mail:wuyi19651007@163.com

$\dagger$ Electronic supplementary information (ESI) available. CCDC 1943540. For ESI and crystallographic data in CIF or other electronic format see DOI: 10.1039/c9ra07216k cation with cyclic ketones for the synthesis of spiro-4-oxazolidinones. ${ }^{11 a}$ In 2018, Alla and co-workers described a coppercatalyzed one-pot multicomponent protocol for the synthesis of spiro(indoline-3,5'-oxazolidine)-2,2'-diones starting from ketones, arylacetylenes and isocyanates. ${ }^{11 b}$

Recently, the transition-metal-catalyzed addition of organoboron reagents to nitriles has received remarkable progress, ${ }^{12}$ since the elegant works on the addition of arylpalladium species to the cyano group reported by Larock and Lu et al. ${ }^{13}$ in which nitriles served as $\mathrm{C}$ building blocks and provided aryl ketones. In virtue of palladium-catalyzed tandem addition of organoboron reagents to nitriles/cyclization protocol, this approach enabled the combination of organoboron reagents and nitriles to construct a diversity of nitrogen-containing heterocycles such as 2-aminobenzophenones, benzofurans, and indoles, in which nitrile serves as $\mathrm{C}-\mathrm{N}$ synthon instead and is incorporated into heterocyclic frameworks in an atom-economical fashion. ${ }^{14}$ However, the development of transition-metal-catalyzed tandem sequence involving the addition of organoboron reagents to nitriles to construct structural novel threedimensional architectures such as spirocyclic systems is still undeveloped.

We have recently developed both intramolecular and intermolecular cyclization approaches to prepare indole and thiophene fused polycyclic derivatives via Pd-catalyzed direct $\mathrm{C}-\mathrm{H}$ bond addition to nitriles. ${ }^{15}$ Given the promising biological

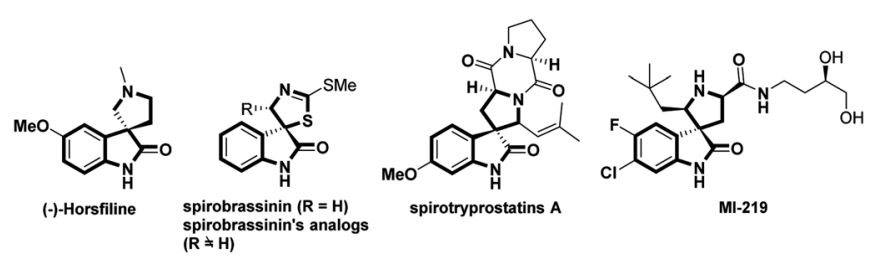

Fig. 1 Examples of spiro oxindoles containing natural products and biological relevant compounds. 
activities of spirooxindoles-containing molecules in medicinal chemistry and our ongoing interest in the development of efficient catalytic processes to prepare diverse aza-heterocyclic frameworks, herein, we report an efficient synthetic approach to prepare spirooxindolyl oxazol-2(5H)-ones via palladium(II)catalyzed addition of arylboronic acids to nitriles.

As functionalized nitriles, cyanohydrins which are readily prepared from ketones and aldehydes have demonstrated considerable synthetic potential as useful building blocks. ${ }^{16} \mathrm{We}$ chose the $\mathrm{Pd}(\mathrm{II})$-catalyzed reaction of 3-cyano-1-methyl-2oxoindolin-3-yl ethyl carbonate 1a, which is readily prepared from isatin and ethyl cyanoformate, and phenylboronic acid 2a as a model reaction for the optimization of the reaction conditions (Table 1). Initially, we examined the reactions in various solvents in the presence of $\mathrm{Pd}(\mathrm{OAc})_{2}(10 \mathrm{~mol} \%), 2,2^{\prime}$ bipyridine (L1: bpy) (12 mol\%) and HOAc (10 equiv.) at $80^{\circ} \mathrm{C}$. To our delight, the desired spirooxindolyl oxazol-2 $(5 H)$-one 3aa was observed in range of solvents, in which low yield was obtained in less polar solvent along with the small amount of byproduct 4a (Table 1, entry 1), while moderate yields were obtained in polar solvents in general (Table 1, entries 2-5). Replacing $\mathrm{Pd}(\mathrm{OAc})_{2}$ with $\mathrm{Pd}(\mathrm{acac})_{2}$ afforded the cyclized product $3 \mathrm{aa}$ in the increased yield in NMP, while $\operatorname{Pd}(\mathrm{TFA})_{2}$ gave the slightly

Table 1 Effects of reaction parameters ${ }^{a}$

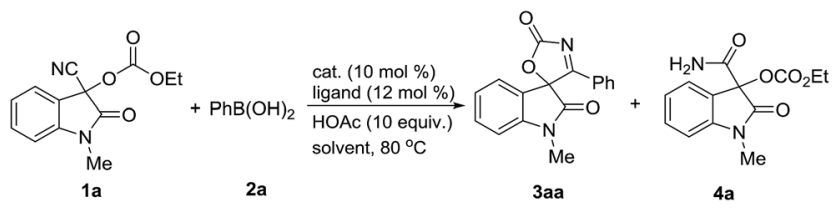

\begin{tabular}{|c|c|c|c|c|c|}
\hline Entry & Cat. & Ligand & Solvent & $\begin{array}{l}t \\
\text { (h) }\end{array}$ & Yield $^{b}(\%)$ \\
\hline 1 & $\mathrm{Pd}(\mathrm{OAc})_{2}$ & L1 & Toluene & 24 & 27 \\
\hline 2 & $\mathrm{Pd}(\mathrm{OAc})_{2}$ & L1 & THF & 24 & 77 \\
\hline 3 & $\mathrm{Pd}(\mathrm{OAc})_{2}$ & L1 & DMF & 24 & 79 \\
\hline 4 & $\mathrm{Pd}(\mathrm{OAc})_{2}$ & L1 & DMSO & 24 & 71 \\
\hline 5 & $\mathrm{Pd}(\mathrm{OAc})_{2}$ & L1 & NMP & 24 & 82 \\
\hline 6 & $\mathrm{Pd}(\mathrm{TFA})_{2}$ & L1 & NMP & 24 & 77 \\
\hline 7 & $\operatorname{Pd}(\text { acac })_{2}$ & L1 & NMP & 24 & 88 \\
\hline 8 & $\operatorname{Pd}(\text { acac })_{2}$ & L2 & NMP & 24 & 86 \\
\hline 9 & $\operatorname{Pd}(\text { acac })_{2}$ & L3 & NMP & 24 & 73 \\
\hline 10 & $\operatorname{Pd}(\mathrm{acac})_{2}$ & L4 & NMP & 24 & 88 \\
\hline $11^{c, d}$ & $\mathrm{Pd}(\mathrm{OAc})_{2}$ & L1 & NMP & 36 & 91 \\
\hline $12^{c, e}$ & $\mathrm{Pd}(\mathrm{OAc})_{2}$ & L1 & NMP & 36 & 83 \\
\hline $13^{e}$ & - & L1 & NMP & 24 & nd \\
\hline $14^{e}$ & $\mathrm{Pd}(\mathrm{OAc})_{2}$ & - & NMP & 24 & nd \\
\hline $15^{d}$ & - & - & NMP & 24 & nd \\
\hline $16^{c, d_{2} f}$ & $\mathrm{Pd}(\mathrm{OAc})_{2}$ & L1 & NMP & 36 & 79 \\
\hline $17^{g}$ & $\mathrm{Ni}(\text { acac })_{2}$ & L2 & MTBE & 24 & 67 \\
\hline
\end{tabular}

${ }^{a}$ Reaction conditions: $1 \mathrm{a}(0.2 \mathrm{mmol}), \mathbf{2 a}(0.6 \mathrm{mmol})$, catalyst (10 mol\%), ligand $(12 \mathrm{~mol} \%)$ and HOAc (10 equiv.) in solvent $(1 \mathrm{~mL})$ at $80{ }^{\circ} \mathrm{C}$. ${ }^{b}$ Isolated yields. ${ }^{c} \mathrm{Pd}(\mathrm{OAc})_{2}(5 \mathrm{~mol} \%)$ and bpy $(6 \mathrm{~mol} \%)$ were used. ${ }^{d}$ HOAc (5.0 equiv.) was used. ${ }^{e}$ Without HOAc. ${ }^{f} 2 \mathrm{a}(0.4 \mathrm{mmol})$ was used. ${ }^{g} \mathrm{Ni}(\mathrm{acac})_{2}(10 \mathrm{~mol} \%), \mathbf{L 2}(12 \mathrm{~mol} \%)$ and $\mathrm{Cs}_{2} \mathrm{CO}_{3}(20 \mathrm{~mol} \%)$ in MTBE $(1 \mathrm{~mL})$ at $110{ }^{\circ} \mathrm{C}$. L1: 2,2'-bipyridine; L2: 4,4'-dimethyl-2,2'bipyridine; L3: 5,5'-dimethyl-2,2'-bipyridine; L4: 1,10-phenanthroline. decreased yield (Table 1, entries 6 and 7). Subsequently, the effect of ligands was evaluated in the presence of $\mathrm{Pd}(\mathrm{acac})_{2}$. The similar results were obtained when 4,4'-dimethyl-2,2'-bipyridine (L2) and 1,10-phenanthroline (L4)were employed respectively, while 5, $5^{\prime}$-dimethyl-2,2'-bipyridine (L3) gave the marginal reducing yield of $3 \mathbf{a}$ (Table 1 , entries $8-10$ ). Notably, the similar efficiency can be observed in prolonged reaction time by using $\mathrm{Pd}(\mathrm{OAc})_{2}$, in which $91 \%$ yield can be obtained in the presence of $\mathrm{Pd}(\mathrm{OAc})_{2}(5 \mathrm{~mol} \%)$ and HOAc (5.0 equiv.) for 36 hours (Table 1 , entry 11). The obvious decline in the yield of product 3aa was observed without HOAc (Table 1, entry 12), while HOAc cannot promote this reaction alone (Table 1, entry 15). Both ligand and $\operatorname{Pd}($ II) catalyst proven to be essential to this transformation since no reaction happened without them (Table 1, entries 13 and 14). The attempt to reducing the amount of $2 \mathrm{a}$ resulted in the decreased yield (Table 1, entry 16). Further survey on other reaction parameters such as additives, reaction temperature and concentration did not improve the chemical outcome of this transformation (for details see the ESI $\dagger$ ). In addition, the reaction also was evaluated with $\mathrm{Ni}$ (II) catalyst system. However, $\mathrm{Ni}(\mathrm{II})$-catalyzed reaction gave the inferior to that of $\mathrm{Pd}(\mathrm{II})$ catalytic system (Table 1, entry 17), and delivered the desired product 3aa in moderate yield under the optimized reaction conditions (Ni(acac) $)_{2}(10 \mathrm{~mol} \%) \mathbf{L} 2(12 \mathrm{~mol} \%)$ and MTBE) (for details see the ESI $\dagger$ ).

With the optimized reaction conditions in hand, the generality of the Pd-catalyzed addition/cyclization sequence for the preparation of spirooxindolyl oxazol-2(5H)-ones was evaluated by employing various isatin based-O-ethoxycarbonyl cyanohydrins 1 and phenylboronic acid 2a first (Scheme 1). Other than $N$-methyl substrate 1a, cyanohydrin analogues $\mathbf{1}$ bearing different $N$-substituents such as phenyl, benzyl, $p$-methoxybenzyl and $p$-nitrobenzyl can give the desired products $\mathbf{3 b a}-\mathbf{3 e a}$ in high yields. The substitution pattern at the benzene ring of cyanohydrins 1 has little influence on the results, and high yields could be obtained (3fa-3ia). In addition, the reactions between substrates possessing both electron-donating ( $\mathrm{MeO}$ and $\mathrm{Me}$ ) and electron-withdrawing ( $\mathrm{NO}_{2}, \mathrm{Br}, \mathrm{Cl}$ and I) substituents at the benzene ring and phenylboronic acid 2 a proceeded well, and gave the corresponding products with excellent yields (3ja-3oa). The structures of spirooxindolyl oxazol-2(5H)-ones were unambiguously confirmed by the exemplification of X-ray crystal structural analysis of product $3 \mathbf{a a} .{ }^{17}$

Next, the substrate scope with respect to arylboronic acids was also investigated, the results of which are summarized in Scheme 2. Arylboronic acids bearing both electron-donating (3ab-3ad) and electron-withdrawing substituents (3ae-3ag) at the benzene ring were tolerated, affording the desired products in good to high yields, exception for strong electronwithdrawing substituent such as nitro group (3ah), which did not react with 3-cyano-1-methyl-2-oxoindolin-3-yl ethyl carbonate 1a. It is noteworthy that the reaction also proceeded smoothly when a substituent was situated at the ortho position of the arylboronic acid, albeit with the slightly decreased yield (3ai). As expected, meta- and di-substituted analogues afforded products (3aj and 3ak) in high yields. Additionally, aryl boronic acids with fused ring also gave their corresponding products 


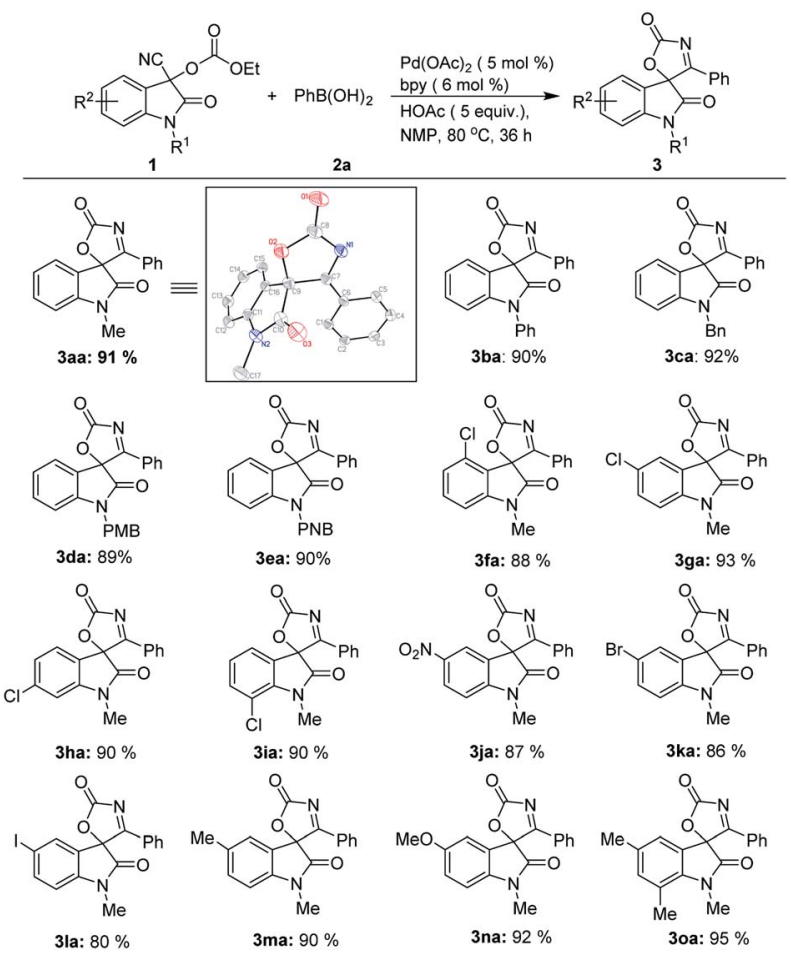

Scheme 1 Substrate scope for preparation of spirooxindolyl oxazol2(5H)-ones ${ }^{a}$. ${ }^{a}$ Reaction conditions: $1(0.3 \mathrm{mmol}), 2 \mathrm{a}(0.9 \mathrm{mmol})$, $\mathrm{Pd}(\mathrm{OAc})_{2}(5 \mathrm{~mol} \%)$, bpy (6 mol\%), HOAc (5 equiv.) in NMP $(1.5 \mathrm{~mL})$ at $80{ }^{\circ} \mathrm{C}$ for $36 \mathrm{~h}$. Yields shown are of isolated products. $\mathrm{PMB}=p$ methoxybenzyl; PNB $=p$-nitrobenzyl.

with high yields. For examples, treatment of both $\alpha$-naphthyl and $\beta$-naphthyl boronic acids with 1a can deliver the corresponding products (3al-3am) in high yields under the

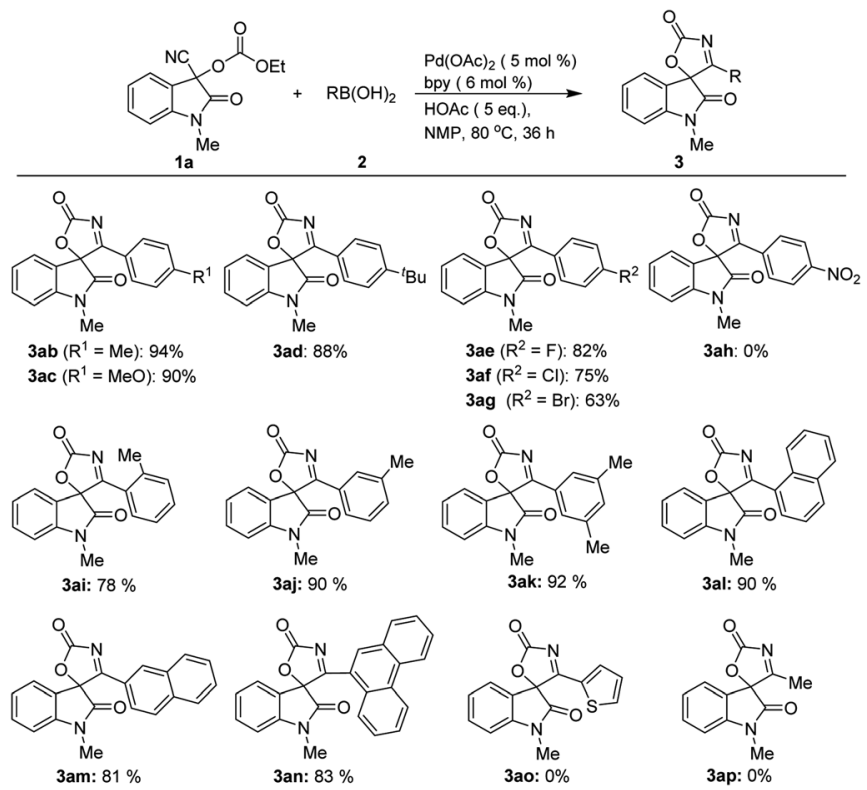

Scheme 2 Substrate scope with respect to boronic acids ${ }^{a}$. ${ }^{a}$ Reaction conditions: 1a $(0.3 \mathrm{mmol}), 2(0.9 \mathrm{mmol}), \mathrm{Pd}(\mathrm{OAc})_{2}(5 \mathrm{~mol} \%)$, bpy (6 mol\%), HOAc (5 equiv.) in NMP $(1.5 \mathrm{~mL})$ at $80{ }^{\circ} \mathrm{C}$ for $36 \mathrm{~h}$. Yields shown are of isolated products. optimized reaction conditions, while 9-phenanthreneboronic acid gave spirooxindolyl product 3an in $83 \%$ yield. However, hetero-aromatic boronic and alkyl boronic acid did not provided any desired products (3ao-3ap).

In addition, besides spirooxindolyl oxazol-2 $(5 H)$-one frameworks, this approach is also applicable to the construction of other spirocyclic frameworks incorporating oxazol-2 $(5 H)$-one unit via palladium-catalyzed tandem sequence (Scheme 3). For example, treatment of 1-cyanocyclopentyl ethyl carbonate 5a with 2a can furnish 4-phenyl-1-oxa-3-azaspiro[4.4]non-3-en-2one $6 \mathbf{a}$ in $84 \%$ yield, while six-membered-ring analogues delivered the corresponding six-membered ring fused spiro-products $(\mathbf{6 b}-\mathbf{6 c})$ in high yields. Cyanohydrin $5 \mathbf{d}$ derived from 2-indanone can also serve as a suitable substrate for this tandem sequence, and provided the desired spiro-product $\mathbf{6 d}$ in $81 \%$ yield.

Finally, the synthetic utility of this Pd-catalyzed cyclization was demonstrated (Scheme 4). The reduction of 3aa by using $\mathrm{BH}_{3} \cdot \mathrm{SMe}_{2}$ readily gave spirooxindolyl product 7 bearing the oxazolidine unit in good yield with an excellent diastereoselectivity.

On the basis of these results and other processes involving the addition of arylpalladium species to nitrile, ${ }^{14,15}$ a plausible mechanism was illustrated in Scheme 5. First, the transmetalation of arylboronic acid by $\operatorname{Pd}(\mathrm{II})$ catalyst $\mathbf{A}$ generates arylpalladium species $\mathbf{B}$. Then coordination of the nitrile provides intermediate $\mathbf{C}$, which undergoes a carbopalladation of the cyano group to result in formation of the corresponding ketimine Pd(II) complex D. The intramolecular cyclization of the intermediate $\mathbf{D}$ to form palladium complex $\mathbf{E}$ which affords product and regenerates the $\mathrm{Pd}(\mathrm{II})$ catalyst.

In summary, we have demonstrated an efficient protocol for the synthesis of spirooxindolyl oxazol-2(5H)-ones via $\operatorname{Pd}(\mathrm{II})$ catalyzed addition of arylboronic acids to nitriles. A diversity of

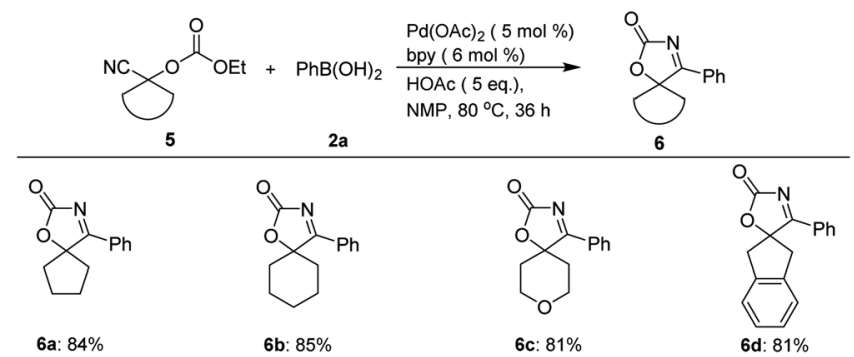

Scheme 3 Preparation of other spirocyclic frameworks ${ }^{a}$. ${ }^{a}$ Reaction conditions: $5(0.3 \mathrm{mmol}), 2 \mathrm{2a}(0.9 \mathrm{mmol}), \mathrm{Pd}(\mathrm{OAc})_{2}(5 \mathrm{~mol} \%)$, bpy (6 mol\%), HOAc (5 equiv.) in NMP $(1.5 \mathrm{~mL})$ at $80{ }^{\circ} \mathrm{C}$ for $36 \mathrm{~h}$. Yields shown are of isolated products.
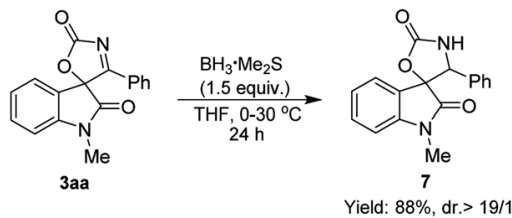

Scheme 4 Synthetic transformation. 


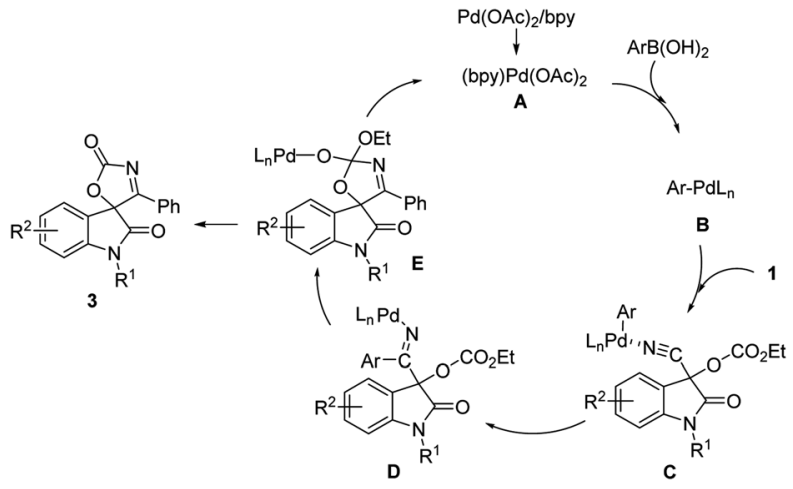

Scheme 5 Proposed mechanism.

functionalized spirooxindolyl oxazol-2(5H)-ones can be prepared in good to high yields under the optimal conditions. Furthermore, by the virtue of this Pd-catalyzed sequence, other five- and six-membered ring fused spiro-oxazol-2 $(5 H)$-ones can be readily prepared in good yields. Further studies on the application of this synthetic method are currently under investigation.

\section{Conflicts of interest}

There are no conflicts to declare.

\section{Acknowledgements}

The NSFC (No. 21772063) and the Open Project of State Key Laboratory for Supramolecular Structure and Materials (sklssm2019016) are acknowledged. This research was supported by China Scholarship Council.

\section{Notes and references}

1 For recent reviews, see: (a) H. Guo, J.-W. Yang and R. Ramon, Chem. Soc. Rev., 2018, 47, 5946; (b) X. Xie, C. Peng and B. Han, Adv. Synth. Catal., 2018, 360, 194; (c) S. D. Griggs, D. T. Tape and P. A. Clarke, Org. Biomol. Chem., 2018, 16, 6620; (d) F. V. Singh, P. B. Kole, S. R Mangaonkar and S. E. Shetgaonkar, Beilstein J. Org. Chem., 2018, 14, 1778; (e) P.-W. Xu, J.-S. Yu and J. Zhou, ACS Catal., 2019, 9, 1820.

2 (a) E. V. Mercado-Marin, R. G. Berlinck and R. Sarpong, Nature, 2014, 509, 318; (b) Z. Bian, C. C. Marvin and S. F. Martin, J. Am. Chem. Soc., 2014, 136, 14184; (c) Z. Bian, C. C. Marvin and S. F. Martin, J. Am. Chem. Soc., 2013, 135, 10886; (d) A. K. Gupta, M. Bharadwaj and R. Mehrotra, Top. Curr. Chem., 2017, 375, 3; (e) Y.-T. Yang, J.-F. Zhu and B. Yu, Curr. Med. Chem., 2018, 25, 2233.

3 (a) A. Jossang, P. Jossang, H. A. Hadi and B. Bodo, J. Org. Chem., 1991, 56, 6527; (b) C. B. Cui, H. Kakeya and H. Osada, Tetrahedron, 1996, 52, 12651; (c) M. Takasugi, K. Monde and A. Shirata, Chem. Lett., 1987, 16, 1631; (d) X. Jiang, Y. Cao and R. Wang, J. Am. Chem. Soc., 2010, 132,
15328; (e) P. Zou, N. Zheng, S.-H. Yu and D.-X. Sun, J. Pharm. Pharm. Sci., 2012, 15, 265.

4 For recent reviews, see: (a) G.-J. Mei and F. Shi, Chem. Commun., 2018, 54, 6607; (b) G. M. Ziarani, R. Moradi and N. Lashgari, Tetrahedron, 2018, 74, 1323; (c) L.-J. Yan and Y.-C. Wang, ChemistrySelect, 2016, 1, 6948; (d) D. Cheng, Y. Ishihara and C. F. Barbas, ACS Catal., 2014, 4, 743.

5 (a) D. J. Ager, I. Prakash, B. Tian and D. R. Schaad, Chem. Rev., 1996, 96, 835; (b) L. Aurelio, R. T. C. Brownlee and A. B. Hughes, Chem. Rev., 2004, 104, 5823.

6 K. Ando, T. Yamada and M. Shibuya, Heterocycles, 1989, 29, 2209.

7 A. Arnoldi, E. Betto, G. Farina and A. Griffini, Pestic. Sci., 1982, 13, 670.

8 (a) R. Somanathan, I. A. Rivero, G. I. Nunez and L. H. Hellberg, Synth. Commun., 1994, 24, 1483; (b) K. Michalska, I. Karpiuk and S. Tyski, Bioorg. Med. Chem., 2013, 21, 577; (c) O. A. Phillips, E. E. Udo and R. Varghese, Eur. J. Med. Chem., 2013, 66, 246; (d) X. Jiang, Y. Cao and R. Wang, J. Am. Chem. Soc., 2010, 132, 15328; (e) T. Xue, B. Guo and Y. Yang, Bioorg. Med. Chem. Lett., 2015, 25, 2203.

9 (a) S. K. Alamsetti, A. K. Å. Persson and J.-E. Bäckvall, Org. Lett., 2014, 16, 1434; (b) D.-Y. Li, H.-J. Chen and P.-N. Liu, Adv. Synth. Catal., 2015, 357, 1193; (c) M. J. Gainer, N. R. Bennett, Y. Takahashi and R. E. Looper, Angew. Chem., Int. Ed., 2011, 50, 684; (d) H.-F. Jiang and J.-W. Zhao, Tetrahedron Lett., 2009, 50, 60.

10 (a) T. Rajasekaran, B. Sridhar and B. V. S. Reddy, Tetrahedron, 2016, 72, 2102; (b) T. Rajasekaran, G. Karthik and B. V. S. Reddy, Org. Lett., 2013, 15, 1512; (c) I. R. Siddiqui, P. Rai and M. A. Waseem, Tetrahedron Lett., 2015, 56, 4367.

11 (a) P.-L. Shao, Z.-R. Li and Y. He, J. Org. Chem., 2017, 82, 10680; (b) G. R. Potuganti, D. R. Indukuri and M. Alla, J. Org. Chem., 2018, 83, 15186.

12 (a) B.-W. Zhao and X.-Y. Lu, Org. Lett., 2006, 8, 5987; (b) Y. C. Wong, K. Parthasarathy and C.-H. Cheng, Org. Lett., 2010, 12, 1736; (c) S. Demir, M. Yiğit and I. Özdemir, J. Organomet. Chem., 2013, 732, 21; (d) M. Yousuf, T. Das and S. Adhikari, New J. Chem., 2015, 39, 8763; (e) J. Sävmarker, J. Rydfjord and M. Larhed, Org. Lett., 2012, 14, 2394.

13 (a) R. C. Larock, Q. Tian and A. A. Pletnv, J. Am. Chem. Soc., 1999, 121, 3238; (b) C. Zhou and R. C. Larock, J. Am. Chem. Soc., 2004, 126, 2302; (c) C. Zhou and R. C. Larock, J. Org. Chem., 2006, 71, 3551; (d) B.-W. Zhao and X.-Y. Lu, Tetrahedron Lett., 2006, 47, 6765.

14 (a) K. Hu, J.-X. Chen and H.-Y. Wu, Green Chem., 2017, 19, 1740; (b) L. Qi, J.-X. Chen and H.-Y. Wu, Org. Lett., 2017, 19, 218; (c) K. Hu, Q. Zhen and J.-X. Chen, Org. Lett., 2018, 20, 3083; (d) J.-H. Zhu, Y.-L. Shao and J.-X. Chen, Org. Biomol. Chem., 2018, 16, 8596; (e) H.-H. Yu, X. Li and L.-M. Shao, Chem. Commun., 2017, 53, 9745; $(f)$ M. Yousuf and S. Adhikari, Org. Lett., 2017, 19, 2214; (g) X.-C. Yang, H.-H. Yu and L.-M. Shao, J. Org. Chem., 2018, 83, 9682.

15 (a) T.-T. Wang, L. Zhao and W.-W. Liao, Org. Lett., 2016, 18, 5002; (b) L. Zhao and W.-W. Liao, Org. Chem. Front., 2018, 5, 801; (c) T.-T. Wang, D. Zhang and W.-W. Liao, Chem. 
Commun., 2018, 54, 2048; (d) D. Zhang, H. Song and W.-W. Liao, Org. Lett., 2019, 21, 2745.

16 For reviews: (a) R. J. H. Gregory, Chem. Rev., 1999, 99, 3649; (b) M. North, Tetrahedron: Asymmetry, 2003, 14, 147; Selected examples: (c) A. Baeza, C. Najera and J. M. Sansano, Synthesis, 2005, 2787; (d) Y. Ogura, M. Akakura and K. Ishihara, Angew. Chem., Int. Ed., 2013, 52, 8299.

17 CCDC 1943540 (compound 3aa), see the ESI for details. $\dagger$ 